\title{
Analysis of Means of Imitation Modeling Used for the Study of Management Processes in Medical Institutions
}

\author{
Vladimir Belov \\ Vice-Rector, Head of the Department of \\ Medical Informatics and Cybernetics \\ Pskov State University \\ Pskov, Russian Federation \\ vsbb@yandex.ru
}

\author{
Alexander Samarkin \\ docent of the Department of Medical \\ Informatics and Cybernetics \\ Pskov State University \\ Pskov, Russian Federation \\ alexsamarkinru@gmail.com
}

\author{
Natalya Ivanova \\ Vice-Rector, Vice-Head of the \\ Department of Medical Informatics and \\ Cybernetics \\ Pskov State University \\ Pskov, Russian Federation \\ vsbb@yandex.ru
}

\begin{abstract}
The article considers the common media of event and multiparadigmatic modelling, as applied to the modelling of the processes of medical institutions to serve the public. The possibilities of managing these processes and optimizing the use of available resources are considered. Formulated recommendations on the use of computer environments in the analysis of business processes and processes of care for the population.
\end{abstract}

Keywords—Analysis, medical, modelling, queuing theory.

\section{INTRODUCTION}

In solving the problems of optimizing and increasing the effectiveness of management processes in health care institutions, one of the most effective research methods consists in organizing and conducting computational experiments with model representations of the object of research - the administrative structure of a medical institution, its individual components (registry, doctor's reception, laboratory services, hospital, etc.) or business processes (exchange of medical data, management accounting, medical examination, rendering of copper Insskoy aid and so on.).

Recently, in Russian [8-20] and foreign [1-7] scientific publications, the issues of simulation modelling of the activities of health organizations have been widely covered. At the same time, models at different levels and directions are built and investigated: "operating" [1], "managing the spread of diseases" [16], "first aid" [5,8], "prophylactic medical examination" [17]. "Management of patients' appeals" [8-10,15,17,19], "management of business processes in a medical organization" $[11-15,18,20,5]$, etc. The purpose of such works is to assess the use of resources of a medical organization and to increase the efficiency of their use and the availability of medical services by patients from healthcare institutions using specialized information technologies of simulation modelling. Imitation (simulation) models make it possible to evaluate, for example, how effectively a medical institution functions in a given working situation, what the burden will be on medical personnel, how quickly the patient will receive medical care from the moment they go to a hospital, etc.
From the point of view of managers of medical organizations, it is methods of simulation that allow to evaluate and compare the effectiveness of a particular strategy of providing patients with access to the resources of a medical institution [8-10,15,19,2]. Simulation models also make it possible to overcome the limitations of analytical methods for conducting model studies of the economic and managerial aspects of health $[11-13,18,20]$. It should be noted that the technology of simulation modelling has such an important advantage over other approaches to the construction and application of models, such as the preservation in the model mappings of the structural features of the organization of the objects of study (in our case, medical organizations), as well as schemes and mechanisms of interaction between the real components of these structures with a friend.

\section{Methodology}

It is known that simulation modelling is based on the following sections of mathematics: control theory, queuing theory, operations research, information processes theory, logistics theory, similarity theory, experiment planning theory. These and other branches of mathematics allowed us to create a number of information environments that implement various approaches and principles of reflecting real objects, real processes of managing healthcare institutions in their simulation models. We note some of these approaches, which are quite widely reflected in the practice of simulation modelling of the activities of medical organizations in serving the public, as well as in analyzing the business processes taking place in them.

GPSS (General Purpose Simulating System) simulation language (see usage examples $[15,19])$, which allows you to build a GPSS model of a technological process of a medical organization or its subdivision as a queuing system, on the basis of which information on loading of individual sections of a medical institution, the presence of queues, the average length of stay of the patient in the system and other data.

IDEF (Integrated Computer Aided Manufacturing Definition) methodology (see application examples in [11$13,18]$ ), included in the SADT recommendations (Structured 
Analysis and Design Technique, Structured Analysis and Design Technique), which is used in analyzing business processes in a medical organization. This methodology uses a process approach $[11,18]$ to formalize the activities of medical institutions and, in general, well reflects the semantics of the subject area - the objects and relationships between them, as well as their main characteristics: execution time and cost of the process, necessary resources (human and material).

The technology of visual direct simulation based on the Unified Modelling Language UML (see [16,20] for examples), which allows interactively investigating eventdriven business processes (including in dynamics) on the model, reflecting the real business processes occurring in the study of the original object (medical institution). Simulation models in the UML environment allow you to recreate the process of passing an object through networks and queues, to make calculations and automatically collect statistical results of model experiments.

The method of discrete event modelling [8-10,3,6,7], based on the use of Matlab high-level simulation language toolkit (Matrix Laboratory - matrix laboratory), which provides the researcher with an interactive environment for programming, numerical calculations and visualization of results. Matlab incorporates an extension package for organizing model studies of systems with discrete states the Simulink visual simulation and situational modelling environment with the SimEvents library (for details on building models, see [8-11]). As an alternative to Simulink $\&$ SimEvents, the Arena Simulation system can be used, an example of which is used in modelling the work of a medical institution described in [3]. The availability of ready-made model blocks in SimEvents, the possibility of creating subunits from them, allows you to build well-structured simulation models and reproduce in model conditions the structures of complex discrete control processes (applying patients to the registry, visiting a doctor, undergoing medical procedures, etc.) in health care institutions and investigating the latter as queuing systems.

The above approaches do not fully cover the range of technical and information techniques for constructing simulation models of medical organizations. Known $[15,6]$ multi-agent methodology of simulation modelling, in particular AnyLogic computer system [14]. Multiagent technologies allow using model objects (modelling individual patients), location objects (reflecting the possible location of agents), as well as the event characteristics of agents (transition from location to location, changing health status) in the model system to reproduce various epidemiological situation, assess the effectiveness of antiepidemic measures, calculate the risks of economic damage from the development of the epidemic.

\section{Discussion}

Analysis of the directions and capabilities of computer simulation tools for management processes in health care organizations listed in section II of this article revealed the following points:

1. The activity of any medical institution that provides health protection and the provision of medical services to the population as an object of research can be viewed from several points of view: first, as a system for managing stochastic structural medical, economic, and administrative components operating under certain resource constraints (medical services, medical personnel); secondly, as a queuing system that provides processing of requests from patients for the provision of medical care or receiving treatment and preventive services; thirdly, as an information-processing environment with developed information-process relations between components, possessing a certain functionality and implementing the necessary business processes in the provision of medical services to patients; fourthly, as a multi-connected medical and economic infrastructure, multivariate use, aimed at providing a variety of more or less regulated processes of medical services to the population.

2. To build a simulation model, it is often necessary to construct a preliminary description of the subject area, taking into account the specific goals of organizing model studies, orientation, terms and notations of selected model computer tools of simulation modelling, ways of visualizing the results of virtual model experiments, ways of interpreting them when developing practical recommendations for organizing activities health care institutions in the provision of medical care and medical diagnostician iCal services to the population, the implementation of health technology, medical and preventive, administrative, economic, financial and other business processes.

3. When studying the characteristics of serving the population in health care institutions, analysing the effectiveness and quality of the provision of treatment-andprophylactic and medical-technological services to patients, the most effective approach to organizing model studies is to represent a medical institution as a mass service system $[8-11,15,19]$. This approach allows you to build software or structural models of the studied system objects (reception, reception at the doctor, receiving medical services, visiting diagnostic laboratories, etc.) and using the results of model experiments to obtain information about the loading of individual windows of the registry, the presence of queues, the average length of stay of the patient in queues at the doctor's office, the average time spent by the patient at the doctor's office, the number of denials of service during the working day, etc. It should be noted here that the Simulink \& SimEvents discrete-event modelling package, which is an extension of Matlab, has a more efficient model tool, which, compared to the GPSS simulation language, has such an important advantage as effective algorithmizing of data processing at the level of structural notations with controlled settings Simulink \& SimEvents effective tools for graphical interpretation of simulation results.

4. For analysing the complexity and efficiency of the implementation of business processes in a medical institution (medical technology, treatment-diagnostic, administrative, economic, organizational) it is preferable to use computer simulation technology using the process approach [11$13,16,18,20]$. Such technologies should well reflect the semantics of the subject area - the objects and connections between them, as well as their main characteristics: the time of execution and the cost of the process, the necessary resources (human, material, financial).

Applied to the problems of studying business processes, simulation technologies based on the IDEF methodology (in particular, the BPMN software - Business Process Model and Notation, notation and business process model), which, unlike the unified modelling language UML, were originally "sharpened" are more effective. on the model visual reconstruction of the organizational structures of institutions, 
the flow of actions (business processes) in them, the processes of information exchange between the components of the structures, internal and external information and ravlyaetsya streams. The BPMN environment allows the model to reproduce three groups of business processes:

- Private business processes that describe the internal activities of the organization - they are combined into a separate pool, while the control flow is inside the pool and cannot cross its boundaries. The message flow, on the other hand, crosses the pool boundaries to display the interaction between different private business processes.

- Abstract (open) business processes that are needed to display the interaction between two private business processes. In an open business process, only those actions that are involved in communication with other processes are shown.

- Interaction processes (global). They display interactions between two or more entities (structural elements of an organization). These interactions are determined by the sequence of actions that process messages between participants.

The use of a unified modelling language UML also makes it possible in general to investigate on models the organization of business processes in specific medical organizations. However, UML is more focused on integrated modelling of event-driven business processes that take place in dynamics, while it is mainly aimed at solving problems of visualization, design and documentation of software systems and, to a lesser extent, at modelling business processes.

5. When solving localized tasks of simulation modelling of medical institutions, such as organizing the activities of a medical institution in case of epidemics, emergencies, etc. It is advisable to use either a multi-agent simulation methodology, if the situation under study has a pronounced stochastic nature, or a discrete-event modelling method, when there is some a priori information about the statistical characteristics of the spread of a disease or about the occurrence of an emergency. Finally, if it is necessary to analyse the effectiveness of organizational patterns of business processes in a medical institution that is transferred to serve the population during mass epidemics or in the event of an emergency, it is advisable to use IDEF simulation methodologies.

\section{CONCluSion}

The elements of the analysis presented in the article make it possible to determine the preferred computer tools and, accordingly, model tools for recreating simulation images (preferably well visualized using graphical notations of selected software) of the objects of study - components of a medical institution, its administrative structural units, business processes, data exchange processes between structural units or business processes, external and internal information on currents. The quality and efficiency of model experiments, the convergence of simulation results and their practical significance in the substantive interpretation and transfer to the actual conditions of functioning of a medical organization largely depends on how successfully the computer system of simulation modelling of a health care institution is selected

\section{REFERENCES}

[1] Barjis J. Healthcare simulation and its potential areas and future trends // SCS M\&S Magazine. - 2011. - № 2 (5). - P. 1-6.

[2] Chonde S., Parra C., Chang C.J. Minimizing flow-time and timeto-first-treatment in an emergency department through simulation Proceedings of the 2013 winter simulation conference. - New Jersey: Institute of electrical and electronics engineers, Inc., 2013. P. 2374-2385.

[3] Kuljis J., Paul R.J., Stergioulas L.K. Can health care benefit from modelling and simulation methods in the same way as business and manufacturing has? // Proceedings of the 2007 winter simulation conference. - IEEE, Piscataway, NJ, 2007. - P. 1449-1453.

[4] Longo F. Emergency simulation: state of the art and futer research guidelines // SCS M\&S Mag. - 2010. - № 4. - P. 1-8. 1

[5] Marshall D.A., Burgos-Liz L., Jzerman M.J. Applying dynamic simulation modelling methods in health care delivery research-the SIMULATE checklist: Report of the ISPOR simulation modelling emerging good practices task force // Value in health. - 2015. - V. 18. Issue 1. - P. 5-16.

[6] White D.L., Froehle C.M., Klassen K.J. The effect of integrated scheduling and capacity policies on clinical efficiency // Prod. oper. manag. - 2011. - № 20 (3) . - P. 442-455.

[7] Zeltyn S., Marmor YN., Mandelbaum avishai and others simulation-based models of emergency departments. Operational, tactical, and strategic staffing // ACM trans. model. comput. simul. - 2011. - № 4 - P. 25.

[8] Belov V.S., Samarkin A.I. Integrated modeling of patient appeals in the medical and preventive institution in Simulink\&SimEvents // Proceeding of the International Scientific Practical Seminar «Electromechanics. Electric Power Engineering. Information Technologies». Pskov, Russia, Pskov State University. - 2018. - P. 111-114 (In Russian).

[9] Belov V.S., Samarkin A.I. Using the Simulink\&SimEvents environment for modeling and evaluation of the efficiency of the work of the registration medical clinic (MC) // Proceeding of the International Scientific Practical Seminar «Electromechanics. Electric Power Engineering. Information Technologies». Pskov, Russia, Pskov State University. - 2018. - P. 115-118 (In Russian).

[10] Belov V.S., Samarkin A.I. Discrete-event simulation of the work of registry offices outpatient clinics by means of Simulink\&SimEvents // Proceeding of the XIII annual all-russian research and practical conference with international participation «health - the base of human potential: problems and ways to solve them». V.13, part 1: SPb. - 2018. - P. 224-232 (In Russian).

[11] Belyshev D.V., Guliev Y.I., Malykh V.L. Business Process Modeling in Healthcare Organizations // Vrach i informatsionnye tekhnologii. - 2014, №5, P. 78-90. (In Russian).

[12] Voronova L.V., Golchevskiy Yu.V. Statistical modeling in management accounting processes by the example of the medical department of the educational institution // Vrach i informatsionnye tekhnologii. - 2014, №3, P. 46-57. (In Russian).

[13] Guliev Ya.I., Belyshev D.V., Mikheev A.E. Modeling of business processes of health facility: classification of processes // Vrach i informatsionnye tekhnologii/ - 2015, №4, P. 6-13. (In Russian).

[14] Kondratyev M. A. Simulation modeling in medicine: multi-agent model of influenza spread // Computer tools in education - 2011, № 4. - P. 32-36. (In Russian).

[15] Seliverstova K.A., Balyasnikova L.D., Luchaninov D.V. Modeling the work of the polyclinic registry // Postulate/ - 2018, № 6. [electronic resource]. Access mode: http://e-postulat.ru/index. php/Postulat/article/download/1605/1639. (In Russian).

[16] Tepluakova E.D., Shcherbakov S.M. Improvement of preventive inspection and clinical examination in outpatient conditions based on simulation // Kuban scientific collection. - 2018, № 4 (153). P. 124-131. (In Russian).

[17] Togunov I.A. Simulation modeling as an information technology for effective managing the relation between public health units Informatsionnye tekhnologii v zdravookhranenii. - 2001, № 2-3. - P. 28-29. (In Russian).

[18] Khairullin I. Process approach and formalization of processes in the activity of medical organization // Quality Management in health care - 2015, № 1. [electronic resource]. Access mode: https:/e.uprzdrav.ru/article.aspx?aid=430907. (In Russian).

[19] Khachumov V. M., Pogodin S. V. Modeling of work of medical institution as system of mass service // Scientific and Technical Information Processing. - 2010. № 1. - P. 49-56. (In Russian).

[20] Shcherbakov S.M., Teplyakova E.D., Rumyantsev S.A., Vasilenok A.V. Simulation for outpatient medical organization management // Social aspects of public health. - 2017, № 4 (56). [electronic resource]. Access mode: http://vestnik.mednet.ru/content/ view/850/30/.(In Russian). 